\title{
HIDRÓLISE DA LACTOSE E PRODUÇÃO DE LEITE EM PÓ: ASPECTOS TECNOLÓGICOS
}

\section{Lactose hydrolysis and milk powder production: technological aspects}

\author{
Jansen Kelis Ferreira Torres ${ }^{1}$, Rodrigo Stephani ${ }^{2}$, Guilherme Miranda Tavares ${ }^{3}$, \\ Antônio Fernandes Carvalho ${ }^{4}$, Renata Golin Bueno Costa ${ }^{5}$, \\ Pierre Schuck ${ }^{6}$, Ítalo Tuler Perrone ${ }^{4 *}$
}

\begin{abstract}
RESUMO
A indústria de alimentos tem como desafio e oportunidade desenvolver novos produtos com reduzido ou baixo teor de lactose, a fim de atender uma crescente massa de portadores de má digestão da lactose. A secagem dos produtos com lactose hidrolisada é um desafio tecnológico devido a higroscopicidade dos mesmos, influenciando na produtividade, no entupimento das câmaras e na conservação dos pós. O objetivo deste estudo foi avaliar o efeito de diferentes níveis de hidrólise enzimática da lactose $(0 \%, 25 \%, 50 \%, 75 \%$ e > 99\%), na produção e estocagem de leite em pó integral utilizando como ferramentas de caracterização dos produtos fabricados em planta piloto a análise de composição, o controle do grau de hidrólise e as isotermas de sorção. Todos os resultados indicam que a hidrólise da lactose afeta a produção do leite em pó por aumentar a adesão no spray dryer e a absorção de umidade durante a estocagem.
\end{abstract}

Palavras-chave: spray dryer; isoterma de sorção; transição vítrea; delactosado.

1 DSM, São Paulo, SP, Brasil.

2 Universidade Federal de Juiz de Fora (UFJF), Juiz de Fora, MG, Brasil.

3 Universidade Estadual de Campinas (UNICAMP), Campinas, SP, Brasil.

4 Universidade Federal de Viçosa (UFV), Av. Peter Henry Rolfs, s/n, Centro, 36570-900, Viçosa, MG, Brasil. E-mail: italotulerperrone@gmail.com

5 Instituto de Laticínios Cândido Tostes/Empresa de Pesquisa Agropecuária de Minas Gerais (ILCT EPAMIG), Juiz de Fora, MG, Brasil.

6 UMR STLO, INRA,Agrocampus-Ouest, França.

* Autor para correspondência.

Recebido / Received: 06/10/2016

Aprovado / Approved: 14/02/2016 


\begin{abstract}
The food industry has the challenge and the opportunity to develop new products with reduced or low lactose content in order to meet the needs of a growing mass of people with lactose intolerance. The manufacture of spray dried products with hydrolyzed lactose is extremely challenging. These products are highly hygroscopic, which influence the productivity and conservation of the powders, not to mention the undesirable and inevitable technological problem of constant clogging of drying chambers. The aim of this study was to evaluate the effect of different levels $(0 \%$, $25 \%, 50 \%, 75 \%$ and $>99 \%$ ) of enzymatic lactose hydrolysis on the production and storage of whole milk powder. The samples were processed in a pilot plant and characterized in relation to their composition analysis; to their degree of hydrolysis of lactose; and to their sorption isotherms. The results indicated the hydrolysis of lactose may affect the milk powder production due to a higher extent of powder adhesion within the spray dryer chambers and due to a higher tendency to absorb water during storage.
\end{abstract}

Keywords: spray dryer; sorption isotherms; glass transition; lactose free.

\section{INTRODUÇÃO}

A intolerância à lactose é o termo comumente usado para descrever sintomas relatados por pessoas que apresentam má digestão da lactose, após ingerirem leite e seus derivados. A má digestão proporciona a presença de lactose no cólon, onde será fonte de energia para a microbiota local. A lactose no cólon será fermentada em ácido lático, resultando na produção de gases como metano, dióxido de carbono e hidrogênio e ácidos graxos de cadeia curta como acético, butírico e propiônico, responsáveis pela redução do pH do meio. Estes compostos são responsáveis pelas flatulências, distensão e dores abdominais. A acidificação do meio, juntamente com o aumento da pressão osmótica, promove a diarréia, com eliminação de eletrólitos e fluídos (GERBAULT et al., 2011; RONG et al., 2011).

Existem três tipos de intolerância a lactose: congênita, primária e secundária. A deficiência congênita se dá pela ausência ou baixa produção da lactase, sendo herdada e extremamente rara. A deficiência primária é a mais frequentemente observada devido ao declínio da atividade enzimática na idade adulta. Em geral, esta queda na produção da lactase varia de acordo com alguns fatores como: quantidade de lactose consumida, idade do indivíduo, genética e taxa de digestão, etc. Somado a estes, existem fatores biológicos, psicológicos e culturais que também podem influenciar no nível de intolerância a alimentos contendo lactose. Já a deficiência secundária, ou deficiência adquirida, é resultante de lesões causadas na mucosa do intestino como, por exemplo, o uso de radiação e de medicação em tratamento de câncer, doenças como gastroenterites, doença de Crohn, colite ulcerativa, dentre outras que também podem lesionar a mucosa intestinal. Sanadas as lesões, geralmente, a atividade da lactase é restabelecida (EUROPEAN FOOD SAFETY AUTHORITY, 2010; LULE et al., 2016; SWALLOW, 2003).

Cerca de $70 \%$ da população mundial adulta apresenta deficiência em níveis de lactase, sendo que na Europa tem sido relatada a variação entre 4\% na Dinamarca e Irlanda e $56 \%$ na Itália. Na América do Sul, África 
e Ásia, mais de 50\% da população apresenta intolerância à lactose. Já em alguns países asiáticos, esta taxa é de quase 100\% (LULE et al., 2016).

De acordo com o levantamento de dados realizado pela Federação Internacional de Laticínios (IDF), o consumo de leite deslactosado na Itália apresentou um crescimento de 7,6\%, em 2014 (IDF, 2015). No Brasil estudos apontam que 5,9\% dos lançamentos de comida e bebida trouxeram informações na embalagem indicando quantidade reduzida ou ausência de lactose, em 2015 (MINTEL, 2016).

O uso da $\beta$-galactosidade, ou lactase, é o principal meio de hidrólise da lactose em produtos lácteos utilizado pelas indústrias (LADERO et al., 2000). Esta enzima pode ser isolada a partir de diferentes fontes, tais como plantas (amêndoas, pêssegos, alperces, maçãs), órgãos de animais, leveduras, bactérias e fungos (RICHMOND et al., 1981).

Quando se utiliza a lactase, diversos fatores devem ser considerados: concentração de substrato, temperatura máxima admissível, tempo de ação, atividade da enzima e o custo. Geralmente a quantidade de enzima a ser utilizada no processo é indicada pelo fornecedor. A temperatura ótima de ação da lactase é de $40{ }^{\circ} \mathrm{C}$, porém é importante controlar o tempo de ação visto que esta temperatura também é ideal para o desenvolvimento de microrganismos no leite. Portanto, o tempo do processo nesta temperatura deve ser de no máximo 4 horas (LADERO et al., 2000; PROZYN, 2010).

A detecção e a quantificação da hidrólise pode ser realizada pelos métodos cromatográficos (MORLOCK et al., 2014), enzimático (CHARNOCK; McCLEARY, 2006), por cloramina T (BRASIL, 2006) e por crioscopia (RODRIGUES JÚNIOR, 2016).

A crioscopia é o método rápido para quantificação da hidrólise da lactose utilizado pelas empresas de laticínios e é baseada na depressão do ponto de congelamento (PROZYN, 2010).

No Brasil não existe uma legislação específica para produtos lácteos com lactose hidrolisada, porém a produção destes atualmente é regulamentada pela Agência Nacional de Vigilância Sanitária (ANVISA), através da Portaria 29 de 13 de janeiro de 1998 que aprova o regulamento técnico referente a alimentos para fins especiais. Este regulamento técnico permite concentração máxima de $0,5 \mathrm{~g}$ de açúcares, neste caso lactose, em $100 \mathrm{~g}$ ou $100 \mathrm{~mL}$ de produto final a ser consumido, para que o produto seja considerado isento desse constituinte (BRASIL, 1998).

De acordo com o Instituto Brasileiro de Geografia e Estatística (IBGE), aproximadamente $44 \%$ dos brasileiros apresentam intolerância à lactose (IBGE, 2014), correspondendo a mais de 90 milhões de brasileiros que não podem consumir ou que consomem de forma moderada produtos de origem láctea.

A secagem de produtos lácteos se caracteriza pela atomização do líquido e evaporação rápida da água na câmara de secagem, aumentando a viscosidade da solução remanescente. Como não existe tempo suficiente para que as moléculas se estabilizem, ocorre a formação de estruturas vítreas antes de se colidirem com outras partículas ou com as paredes do equipamento (ROOS, 2002).

O estado vítreo é evidenciado por uma solução de alta viscosidade com mobilidade molecular limitada. Porém, o produto neste estado é higroscópico e metaestável, ou seja, está vulnerável a alterações de estado físico ou de propriedades físico-químicas durante o processamento, a estocagem e o consumo (ROOS, 2002). A Tg (transição vítrea) consiste em uma mudança do sistema do estado amorfo (estado vítreo) para o estado gomoso. O estado gomoso caracteriza-se por uma solução de baixa viscosidade resultando em mudanças estruturais como o fenômeno de aglomeração, adesão à câmara durante 
o processamento e, com o tempo, podendo alcançar o empedramento (LEITE et al., 2005).

A transição vítrea do leite em pó ocorre a uma determinada temperatura, denominada temperatura de transição vítrea (TTg) que é variável com a composição específica do produto lácteo. A TTg pode ser prevista utilizando a equação de Couchman e Karasz (1978):

$$
T T g=\frac{W 1 \Delta C p 1 T T g 1+W 2 \Delta C p 2 T T g 2+W 3 \Delta C p 3 T T g 3}{W 1 \Delta C p 1+W 2 \Delta C p 2+W 3 \Delta C p 3}
$$

Equação 1 - Temperatura de transição vítrea

sendo: $T T g$ é a temperatura de transição vítrea do componente; $\Delta C p$ é a mudança na capacidade calorífica de cada componente durante a transição vítrea $\left(\mathrm{J} \cdot \mathrm{kg}^{-1}{ }^{\circ} \mathrm{C}^{-1}\right)$ e $W$ é a fração mássica $\left(\mathrm{m} \cdot \mathrm{m}^{-1}\right)$ do componente na mistura.

Na Tabela 1 observa-se que a água é o principal componente responsável pela queda da TTg, sendo considerada um forte plasticizante no produto lácteo (JOUPPILA et al., 1997).

Tabela 1 - Temperatura de transição vítrea dos componentes do leite em pó

\begin{tabular}{cc}
\hline Componente & $\operatorname{TTg}\left({ }^{\circ} \mathrm{C}\right)$ \\
\hline Água & -139 \\
Caseína & 132 \\
Proteínas solúveis & 127 \\
Lactose & 98 \\
Glicose & 31 \\
Galactose & 30 \\
\hline
\end{tabular}

Fonte: Schucket al. (2005a).

$\mathrm{O}$ aumento da temperatura pode induzir a transição vítrea, processo similar ao aumento da concentração de plasticizante, como por exemplo, o aumento da concentração da água (umidade) do produto (ROOS; KAREL, 1991). Durante a secagem por atomização, caso o leite concentrado entre em contato com o ar quente e úmido (elevada umidade relativa), terá dificuldade em evaporar a água, havendo um aumento na concentração de água no produto final. De acordo com Schuck (2016), a TTg do leite em pó desnatado anidro é aproximadamente $92{ }^{\circ} \mathrm{C}$. Porém, se este mesmo pó apresentar 4,4\% $(\mathrm{m} / \mathrm{m})$ de umidade, a sua TTg passa a ser de $45{ }^{\circ} \mathrm{C}$. Este decréscimo ocorre devido a uma maior porcentagem de água no produto (SCHUCK et al., 2005a).

O leite em pó deslactosado (LPD) apresenta além da lactose (em baixas concentrações), a glicose e a galactose. Como apresentado na Tabela 1, estes monossacarídeos apresentam uma TTg menor que a da lactose, visto que a TTg de um carboidrato é inversamente proporcional ao seu peso molecular (ROOS, 1993). Considerando que a TTg do produto lácteo é a resultante dos seus componentes, o LPD apresenta uma TTg menor que a do leite em pó tradicional (SCHUCK et al., 2005a).

Quando a indústria de alimentos produz o LPD com os mesmos parâmetros de secagem utilizados para o leite em pó tradicional, acaba por elaborar um produto completamente diferente em relação à "secabilidade" podendo apresentar aglomeração, aderência à câmara, caking, coloração mais escura e elevação da higroscopicidade. Isso ocorre porque a temperatura do ar de entrada na câmara pode resultar no aquecimento do pó acima da sua TTg, fazendo com que este passe do estado vítreo para o estado gomoso (FERNÁNDEZ et al., 2003; SHRESTHA et al., 2007).

Os problemas apontados na produção do leite em pó deslactosado levam a uma perda na qualidade do pó como, por exemplo, a dificuldade de reidratação, aspectos sensoriais alterados, além de um baixo rendimento 
(FERNÁNDEZ et al., 2003). Diante desses problemas, a indústria busca mudanças significativas na composição e nas condições de secagem do LPD (JOUPPILA; ROOS, 1994).

O objetivo deste estudo foi avaliar o efeito de diferentes níveis de hidrólise enzimática da lactose, $0 \%, 25 \%, 50 \%, 75 \%$ e > $99 \%$, na produção e estocagem de leite em pó integral utilizando como ferramentas de caracterização dos produtos fabricados em planta piloto, a análise de composição, o controle do grau de hidrólise e as isotermas de sorção.

\section{MATERIAL E MÉTODOS}

As atividades deste trabalho foram desenvolvidas em diferentes laboratórios por meio de parcerias em pesquisa entre diferentes instituições, a saber: no Laboratório de Leite e Derivados (INOVALEITE) do Departamento de Tecnologia de Alimentos da Universidade Federal de Viçosa (MG) e na Empresa de Pesquisa Agropecuária de Minas Gerais (EPAMIG), Instituto de Laticínios Cândido Tostes, Juiz de Fora/MG.

O experimento consistiu na hidrólise enzimática da lactose de leite concentrado integral com $40 \%$ de sólidos totais. Foram realizados cinco diferentes tratamentos em relação à hidrólise da lactose: leite concentrado sem hidrólise $(0 \mathrm{H})$, com $25 \%(25 \mathrm{H}), 50 \%(50 \mathrm{H})$, $75 \%(75 \mathrm{H})$ e $>99 \%(99 \mathrm{H})$ de hidrólise, em quatro repetições $(n=4)$, totalizando 20 unidades experimentais.

\section{Hidrólise enzimática da lactose no leite concentrado}

A hidrólise enzimática da lactose foi realizada no leite concentrado integral com $40 \%$ de sólidos totais obtidos a partir da reconstituição do leite em pó integral em água a temperatura de $25{ }^{\circ} \mathrm{C}$. Ao leite concentrado foi adicionado $0,2 \% \mathrm{~m} / \mathrm{m}$ da enzima Maxilact da empresa $\mathrm{DSM}^{\circledR}$, à temperatura de $34{ }^{\circ} \mathrm{C} \pm$ $1{ }^{\circ} \mathrm{C}$. Para a quantificação do grau de hidrólise da lactose foram coletadas amostras antes da adição da lactase e durante o tempo de ação da mesma em intervalos de 10 minutos, até alcançar a hidrólise desejada. As amostras de leite concentrado foram previamente diluídas para $10 \%$ de sólidos totais com água destilada, no intuito de se aproximar das características do leite fluido, de modo a monitorar o grau de hidrólise por meio da crioscopia, (crioscópio ITR MK540 Flex II, Tex Tech, Brasil) (RODRIGUES JUNIOR et al., 2016). Todos os produtos foram submetidos à secagem em Spray Dryer MSD $1.0 \mathrm{com}$ vazão máxima de $1,2 \mathrm{~L} / \mathrm{h}$ de produto, vazão de ar comprimido de $30 \mathrm{~L} / \mathrm{min}$, vazão do ar do soprador de $2,0 \mathrm{~m} 3 / \mathrm{min}$ e um sistema de atomização por bico de pressão com diâmetro de $1 \mu \mathrm{m}$ (LabMaq, Brasil). Os parâmetros de secagem foram fixados em $170{ }^{\circ} \mathrm{C}$ de temperatura do ar de entrada e $85^{\circ} \mathrm{C}$ de temperatura do ar de saída. Ao final da secagem para cada amostra, todo o pó foi coletado do equipamento, embalado a vácuo e estocado em local de temperatura controlada $\left(25^{\circ} \mathrm{C}\right)$ e ao abrigo da luz. Foram coletadas imagens fotográficas, em câmera Motorola modelo MotoG de 13 Mpixel, do equipamento de secagem após a retirada do leite em pó.

\section{Análises físico-químicas}

As amostras dos leites em pó obtidos (RLL) foram analisadas quanto a sua concentração de sólidos totais (ST), teor de proteínas, cinzas, lactose e lipídeos. O teor de ST foi determinado pela técnica gravimétrica, em estufa à temperatura de $105^{\circ} \mathrm{C}$ (AOAC, 1995). Proteína total pelo método micro Kjeldahl (AOAC, 1995) e o teor de cinzas pelo método gravimétrico, avaliando a perda de massa do material submetido à incineração, em mufla a $550^{\circ} \mathrm{C}$ (AOAC, 1995). O teor de lipídeo foi determinado pelo método de 
Gerber (FIL ISO1737). O teor de lactose foi determinado empregando um kit enzimático de quantificação de lactose/D-galactose (CHARNOCK; McCLEARY, 2006) conforme protocolos indicados pelo fornecedor (BEUTLER, 1988). Os pós foram analisados quanto às suas respectivas atividades de água $\left(\mathrm{a}_{\mathrm{w}}\right)$, utilizando equipamento Aqualab (Decagon3TE, Decagon Devices Inc., USA).

\section{Isotermas de sorção}

A análise de isotermas de sorção foi realizada a $25^{\circ} \mathrm{C}$ por meio da busca do equilíbrio entre as amostras e diferentes soluções saturadas de sais em dessecadores durante 21 dias. As soluções salinas saturadas utilizadas e os respectivos valores de atividade de água foram cloreto de lítio ( $\mathrm{LiCl})$ 0,112, acetato de potássio $\left(\mathrm{KC}_{2} \mathrm{H}_{3} \mathrm{O}_{2}\right)$ 0,226, carbonato de potássio $\left(\mathrm{K}_{2} \mathrm{CO}_{3}\right) 0,438$, nitrato de magnésio $\left(\mathrm{Mg}\left(\mathrm{NO}_{3}\right)_{2}\right)$ 0,523, nitrato de amônio $\left(\mathrm{NH}_{4} \mathrm{NO}_{3}\right)$ 0,620 , cloreto de sódio $(\mathrm{NaCl})$ 0,753.

\section{Cálculo da temperatura de transição vítrea}

As temperaturas de transição vítrea foram obtidas por cálculos a partir da equação extendida de COUCHMAN; KARASZ (1978) (equação 1), a qual permite calcular as Tg's de sistemas com mais de dois componentes (FOSTER, 2002). Esta equação tem sido aplicada por diversos autores (ARVANITOYANNIS et al., 1993; KALICHEVSKY et al., 1993; SCHUCK et al., 2005b). Para a realização dos cálculos foram utilizados os valores de $\mathrm{Tg}$ e $\Delta \mathrm{Cp}$ de cada componente presente nos compostos lácteos: lactose $\mathrm{Tg} 98{ }^{\circ} \mathrm{C}, \Delta \mathrm{Cp} 0,38 \mathrm{~J} / \mathrm{kg} \cdot{ }^{\circ} \mathrm{C}$ (SENOUSSI et al., 1995); caseína $\mathrm{Tg} 132^{\circ} \mathrm{C}$, $\triangle \mathrm{Cp} 0,26 \mathrm{~J} / \mathrm{kg}^{\circ} \mathrm{C}$ (MATVEEV et al., 1997); proteínas do soro $\mathrm{Tg} 127{ }^{\circ} \mathrm{C}, \Delta \mathrm{Cp} 0,09 \mathrm{~J} / \mathrm{kg} \cdot{ }^{\circ} \mathrm{C}$ (KALICHEVSKY et al., 1993; MATVEEV et al., 1997; MAUER et al., 2000).

\section{Análise estatística}

Os resultados foram avaliados por análise de variância (ANOVA) e teste de Tukey para a comparação de médias $(\mathrm{p}<0,05)$. Os dados foram analisados por meio do programa estatístico Statistical Analysis System (SAS Institute Inc., 2006) versão 9.2, licenciado para a Universidade Federal de Viçosa/MG.

\section{RESULTADOS E DISCUSSÃO}

\section{Análises físico-químicas}

As amostras de RLL foram caracterizadas quanto a composição e ao valor calculado da temperatura de transição vítrea (TTg) (Tabela 1).

Não foi observada diferença significativa ( $p>0,05)$ quanto aos parâmetros aw, gordura total e proteína total, entre os tratamentos, indicando que o processo de secagem ocorreu de forma controlada, simulando o processamento industrial. Em relação ao conteúdo de umidade dos pós, houve diferença estatística $(\mathrm{p}<0,05)$ entre os tratamentos e observa-se que, com o aumento do nível da hidrólise, há também o aumento do valor da umidade obtida. O incremento no valor da umidade pode ter ocorrido devido a maior tendência a absorção de umidade ambiente apresentada pelos pós sem lactose (Schuck et al., 2005b), principalmente durante o término da secagem, a raspagem do spray dryer e o envase das amostras. As condições de processamento pós secagem em um equipamento piloto permitem grande contato dos produtos com o ar ambiente e consequentemente maior absorção de umidade. Este comportamento é corroborado pelos resultados das isotermas de sorção.

Observa-se que quanto maior foi o grau de hidrólise, mais as curvas da Figura 1 se distanciam do eixo $\mathrm{X}$ (atividade de água). Isso indica que para uma mesma condição 
Tabela 2 - Análises físico-químicas e TTg dos leites em pó hidrolisados $(n=4)$

\begin{tabular}{c|c|c|c|c|c|c|c}
\hline TE & $\begin{array}{c}\text { Umidade } \\
(\mathrm{g} / 100 \mathrm{~g})\end{array}$ & $\mathrm{a}_{\mathrm{w}}$ & $\begin{array}{c}\text { Gordura } \\
(\mathrm{g} / 100 \mathrm{~g})\end{array}$ & $\begin{array}{c}\text { Proteína } \\
(\mathrm{g} / 100 \mathrm{~g})\end{array}$ & $\begin{array}{c}\text { RMF } \\
(\mathrm{g} / 100 \mathrm{~g})\end{array}$ & $\begin{array}{c}\text { Lactose } \\
(\mathrm{g} / 100 \mathrm{~g})\end{array}$ & $\begin{array}{c}\text { TTG } \\
\left({ }^{\mathrm{o}} \mathrm{C}\right)\end{array}$ \\
\hline $0 \mathrm{H}$ & $4,09 \pm 2,11^{\mathrm{a}}$ & $0,19 \pm 0,04^{\mathrm{a}}$ & $23,69 \pm 0,78^{\mathrm{a}}$ & $23,04 \pm 0,80^{\mathrm{a}}$ & $5,99 \pm 0,04^{\mathrm{ab}}$ & $31,64 \pm 0,73^{\mathrm{a}}$ & 108,3 \\
\hline $25 \mathrm{H}$ & $5,71 \pm 1,99^{\mathrm{ab}}$ & $0,17 \pm 0,04^{\mathrm{a}}$ & $23,27 \pm 0,82^{\mathrm{a}}$ & $25,01 \pm 0,54^{\mathrm{a}}$ & $6,00 \pm 0,06^{\mathrm{b}}$ & $22,22 \pm 0,04^{\mathrm{b}}$ & 100,9 \\
\hline $50 \mathrm{H}$ & $6,45 \pm 1,96^{\mathrm{ab}}$ & $0,18 \pm 0,05^{\mathrm{a}}$ & $23,92 \pm 2,39^{\mathrm{a}}$ & $23,65 \pm 0,89^{\mathrm{a}}$ & $5,94 \pm 0,02^{\mathrm{ab}}$ & $13,30 \pm 0,06^{\mathrm{c}}$ & 90,7 \\
\hline $75 \mathrm{H}$ & $9,17 \pm 2,62^{\mathrm{b}}$ & $0,18 \pm 0,02^{\mathrm{a}}$ & $25,09 \pm 1,07^{\mathrm{a}}$ & $23,16 \pm 1,96^{\mathrm{a}}$ & $5,96 \pm 0,03^{\mathrm{ab}}$ & $7,33 \pm 0,14^{\mathrm{d}}$ & 82,8 \\
\hline $99 \mathrm{H}$ & $10,13 \pm 1,68^{\mathrm{b}}$ & $0,21 \pm 0,03^{\mathrm{a}}$ & $24,31 \pm 1,12^{\mathrm{a}}$ & $23,18 \pm 0,94^{\mathrm{a}}$ & $5,88 \pm 0,09^{\mathrm{a}}$ & $1,86 \pm 0,51^{\mathrm{e}}$ & 74,8 \\
\hline
\end{tabular}

sendo: $\mathrm{TE}=$ tratamentos do experimento, $\mathrm{RMF}=$ resíduo mineral fixo, $\mathrm{TTg}=$ temperatura de transição vítrea calculada segundo a Equação 1. Dados de quatro repetições, análises realizadas em duplicata. Médias seguidas de pelo menos uma mesma letra, para cada variável, não diferem entre si ao nível de 5\% de probabilidade pelo teste de Tukey.

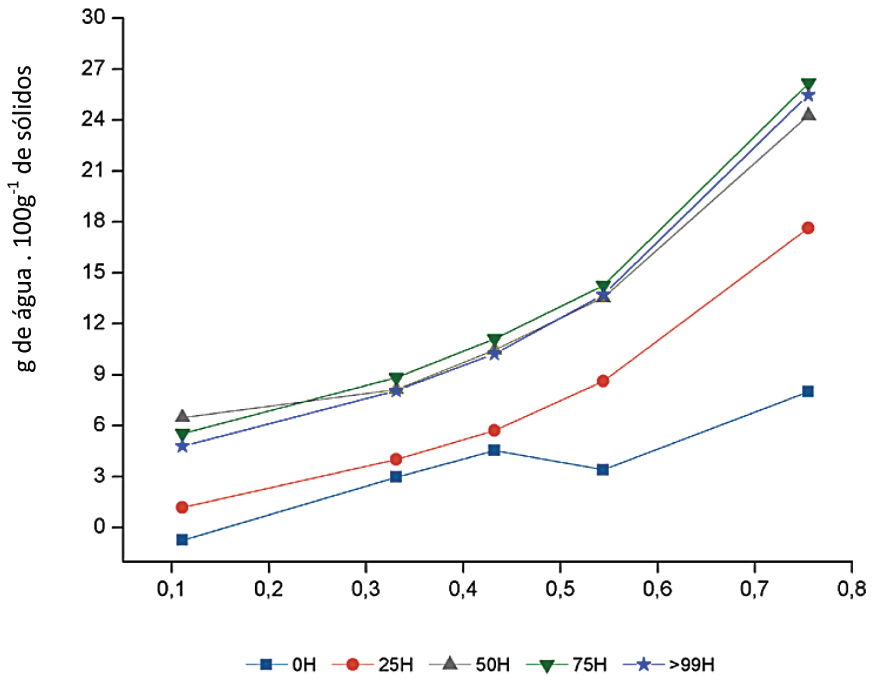

Figura 1 - Isoterma de sorção a $25^{\circ} \mathrm{C}$

de armazenamento do produto a $25{ }^{\circ} \mathrm{C}$ e sob umidade relativa do ar constante que os produtos com graus superiores de hidrólise são capazes de reter mais água por $100 \mathrm{~g}$ de sólidos. O leite em pó não hidrolisado $(0 \mathrm{H})$ apresentou uma depressão na curva entre os valores de 0,5 e 0,6 de atividade de água. Esta depressão é atribuída a cristalização da lactose (ROOS, 2002). A depressão é ausente nos produtos hidrolisados, como esperado, contudo nenhuma outra depressão é observada nestas curvas. A absorção de água nestes produtos deveria implicar em formação de cristais de glicose e de galactose, contudo a ausência de depressões nas curvas de isotermas indica que estes cristais não se formaram. Resultado semelhante, ou seja, ausência de cristalização em produto lácteo desidratados 
com lactose hidrolisada, foi encontrado por Schuck et al. (2005b).

Devido a hidrólise da lactose observase uma redução de até $33,5^{\circ} \mathrm{C}$ nas temperaturas de transição vítreas teóricas (Tabela 1). Observa-se a partir da Tabela 1 que a temperatura de transição vítrea do leite em pó com maior grau de hidrólise $(99 \mathrm{H})$ é de $74,8^{\circ} \mathrm{C}$, e, em um primeiro momento, depreende-se que como o processo de secagem não propicia ao produto temperaturas próximas a este valor que os fenômenos de adesão e empedramento jamais ocorrerão na produção. Contudo, a temperatura de $74,8{ }^{\circ} \mathrm{C}$ para a transição vítrea é relativa ao leite em pó com teor de umidade que tende a zero. Se o leite em pó com maior grau de hidrólise $(99 \mathrm{H})$ estiver em equilíbrio com o ar com $11,0 \%$ de umidade relativa então apresentará umidade de 4,8\% (determinada pela análise de isoterma de sorção) e TTg

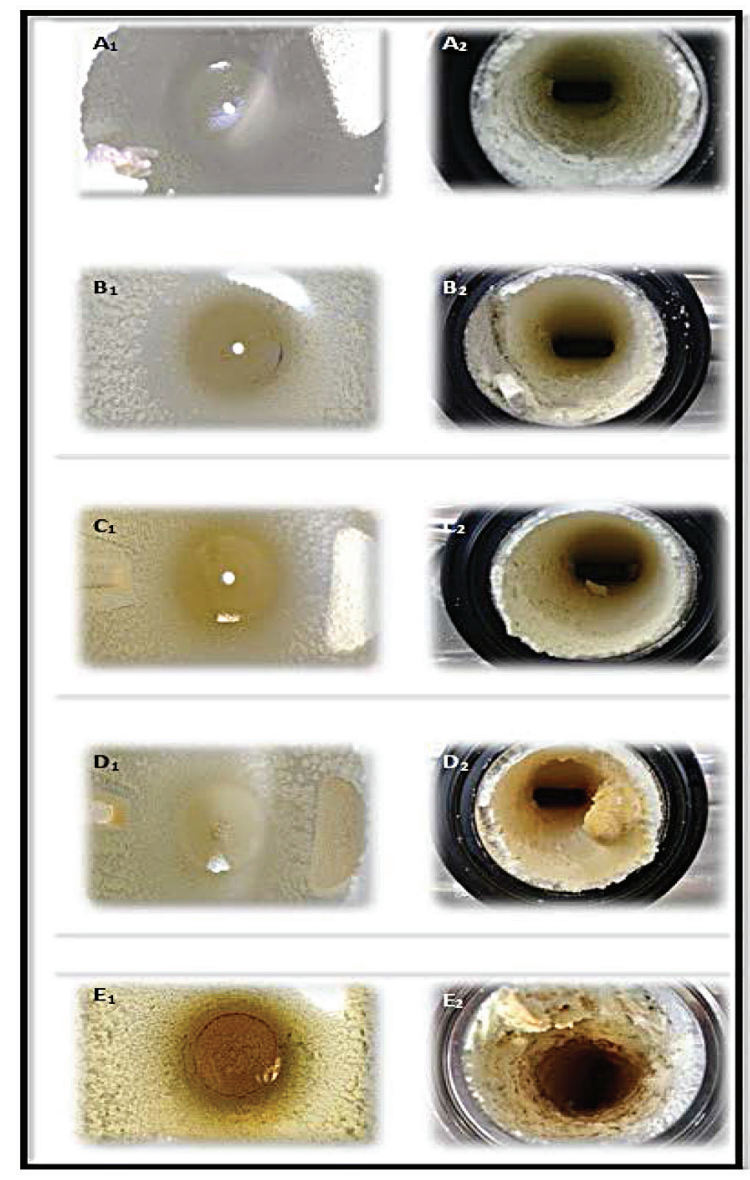

Figura 2 - Comparação por imagens da influência do nível de hidrólise da lactose na secagem do leite em pó integral em spray dryer, em que (A) representa o produto controle sem hidrólise (0H); (B) 25\% (25H), (C) 50\% (50H), (D) 75\% (75H) e (E) > 99\% (99H) de hidrólise da lactose. Respectivamente: interior da câmara de secagem após 1 hora de operação (1) e entrada do ciclone após 1 hora de operação (2). 
calculada de $-14,8^{\circ} \mathrm{C}$. O comportamento que se observa aqui consiste na capacidade das moléculas de água de contribuírem para a diminuição da $\mathrm{Tg}$ dos produtos (SCHUCK et al., 2005a).

A Figura 2 apresenta as fotos do spray dryer após as secagens.

Conforme apresentado na Figura 2, os RLL $(25 \mathrm{H}, 50 \mathrm{H}, 75 \mathrm{H}$ e $99 \mathrm{H})$ obtidos nos tratamentos demonstraram maior aderência à câmara de secagem conforme o aumento do nível de hidrólise da lactose, quando comparados ao produto controle $(0 \mathrm{H})$. Comportamento semelhante também foi observando em relação à cor dos produtos, a qual denotasse escurecimento progressivo mediante o incremento da hidrolise.

Os RLL apresentam além da lactose (em diferentes concentrações), glicose e galactose. Estes monossacarídeos apresentam uma temperatura de transição vítrea menor que a da lactose, visto que a $\mathrm{Tg}$ de um carboidrato é inversamente proporcional à sua massa molecular (ROOS, 1993). Considerando que a $\mathrm{Tg}$ do produto lácteo é a resultante dos seus componentes, os RLL apresentam uma temperatura de transição vítrea menor que a do leite em pó tradicional (SCHUCK et al., 2005a).

A indústria de alimentos ao produzir os RLL com os mesmos parâmetros de secagem utilizados para o leite em pó tradicional se depara com um produto completamente diferente em relação à secabilidade podendo apresentar aglomeração, aderência à câmara, caking, coloração mais escura e elevação da higroscopicidade. Isso ocorre porque as temperaturas do ar de entrada e saída na câmara podem resultar no aquecimento do pó acima da sua TTg, fazendo com que este passe do estado vítreo para o estado gomoso (FERNÁNDEZ et al., 2003; SHRESTHA et al., 2007).

Um dos pontos negativos mais evidentes do escurecimento dos alimentos e dos produtos formados a partir dele corresponde à destruição ou redução do valor nutricional de aminoácidos essenciais como arginina, lisina, metionina e triptofano, além de redução da digestibilidade do alimento (IKAN, 1996; MARTINS et al., 2001; YILDIZ, 2010). A lisina, por apresentar o grupo amino épsilon livre, apresenta alta reatividade sendo mais susceptível à reação (carbonila-ami no) o que pode reduzir o valor nutricional do alimento (ARAÚJO, 2008; BASTOS et al., 2011; FENNEMA, 2010; NUNES; BAPTISTA, 2001).

Shrestha et al. (2007) concluíram que a secagem por atomização do leite desnatado em pó contendo lactose hidrolisada resultou em um baixo rendimento na produção, sendo que uma grande quantidade de pó permaneceu aderida no equipamento e apenas $25 \%$ do pó foi recuperado no ciclone. A TTg do pó deslactosado anidro foi de $49^{\circ} \mathrm{C}$.

Fernández, Schebor e Chirife (2003) observaram que o leite em pó deslactosado apresentou uma coloração escura quando comparado ao leite em pó tradicional. Este fenômeno é devido a maior disponibilidade de açúcares redutores na sua composição, favorecendo a reação de Maillard.

Os problemas apontados na produção do leite em pó deslactosado leva a uma perda na qualidade do pó, como por exemplo dificuldade de reidratação, aspectos sensoriais alterados, além de um baixo rendimento (FERNÁNDEZ et al., 2003). Diante desses problemas, a indústria busca mudanças significativas na composição e nas condições de secagem do leite em pó deslactosado (JOUPPILA; ROSS, 1994).

\section{CONCLUSÃO}

Os diferentes níveis de hidrólise enzimática da lactose no leite concentrado influenciam nas características de secagem em spray dryer do leite em pó integral com a 
aglomeração e adesão de partículas dos pós nas superfícies do equipamento e também ao escurecimento dos RLL com o aumento da hidrólise. A composição físico-química dos RLL é alterada, além da lactose, apenas no teor de umidade, contudo com o aumento da hidrólise existe um aumento da tendência a absorção da umidade ambiente o que foi evidenciado pelas isotermas de sorção.

\section{AGRADECIMENTOS}

Os autores agradecem pelo suporte financeiro e por concessão de bolsas os órgãos FAPEMIG, CNPq e CAPES.

\section{REFERÊNCIAS}

ARVANITOYANNIS, I. et al. Calorimetric Study of the Glass Transition Occurring in Fructose Solutions. Carbohydrate Research, v. 246, p. 13-22, 1993.

BEUTLER, H. O. Lactose and D-Galactose. In Methods of Enzymatic Analysis (Bergmeyer, H. U., ed.), 3rd ed., Vol. VI, pp. 104-112, 1988.

BRASIL. Ministério da Agricultura, Pecuária e Abastecimento. Portaria $n^{\circ} 369$, de 04 de setembro de 1997. Aprova o Regulamento Técnico de Identidade e Qualidade do Leite em Pó. Diário Oficial da República Federativa do Brasil. Brasília, 08 set. 1997, Seção 1, p. 19699.

Ministério da Saúde. Portaria $n^{\circ} 29$ de 13 de janeiro de 1998. Regulamento Técnico Referente a Alimentos para Fins Especiais. Diário Oficial da República Federativa do Brasil. Brasília, 15 jan. 1998, Seção I-E, p. 8.

Ministério da Agricultura, Pecuária e Abastecimento. Instrução Normativa $\mathrm{n}^{\circ}$ 68, de 12 de dezembro de 2006. Oficializa os métodos analíticos oficiais físico-químicos, para controle de leite e produtos lácteos. Diário Oficial da República Federativa do Brasil., Brasília, 14 dez. 2006. Seção 1, p.8.

COUCHMAN, P. R.; KARASZ, F. E. A Classical Thermodynamic Discussion of the Effect of Composition on Glass-Transition Temperatures. Macromolecules, v. 11, n. 1, p. 117-119, 1978.

FERNÁNDEZ, E.; SCHEBOR, C.; CHIRIFE, J. Glass transition temperature of regular and lactose hydrolyzed milk powders. LWT Food Science and Technology, v. 36, n. 5, p. 547-551, 2003.

GERBAULT, P. et al. Evolution of lactase persistence: an example of human niche construction. Philosophical Transactions of the Royal Society B: Biological Sciences, v. 366, n. 1566, p. 863-877, 2011.

INSTITUTO BRASILEIRO DE GEOGRAFIA E ESTATÍstiCA - IBGE. Produção da Pecuária Municipal. v. 42, p. 1-63, 2014.

INTERNATIONAL DAIRY FEDERATION (IDF). The World Dairy Situation 2015. Bulletin of the International Dairy Federation, p. 260, 2015.

JOUPPILA, K.; KANSIKAS, J.; ROOS, Y. H. Glass Transition, Water Plasticization, and Lactose Crystallization in Skim Milk Powder. Journal Dairy of Science, v. 80, n. 12, p. 3152-3160, 1997.

JOUPPILA, K.; ROOS, Y. H. Water sorption and time-dependent phenomena of milk powders. Journal of Dairy Science, v. 77, n. 7, p. 1798-1808, 1994.

JOUPPILA, K.; ROOS, Y. H. Glass Transitions and Crystallization in Milk Powders. Journal 
of Dairy Science, v. 77, n. 10, p. 2907-2915, 1994.

LADERO, M.; SANTOS, A.; GARCIAOCHOA, F. Kinetic modeling of lactose hydrolysis with an immobilized $\beta$ - galactosidase from Kluyveromyces fragilis. Enzyme and Microbial Technology, v. 27, n. 8, p. 583-592, 2000.

LE, THAO T. et al. Maillard reaction and protein cross-linking in relation to the solubility of milk powders. Journal of Agricultural and Food Chemistry. 59.23 (2011): 1247312479.

LE, THAO T. et al. "Direct evidence for the role of Maillard reaction products in protein cross-linking in milk powder during storage". International Dairy Journal. 31.2 (2013): 83-91.

LEITE, J. T. C.; MURR, F. E. X.; PARK, K. J. Transições de fases em alimentos: influência no processamento e na armazenagem. Revista Brasileira de Produtos Agroindustriais, v. 7, p. 83-96, 2005.

LONGO, G. Influência da adição de lactase na produção de iogurtes. s.1: s.n., 2006.

LULE, V. K. et al. Food Intolerance: Lactose Intolerance. Encyclopedia of Food and Health, n. September 2015, p. 43-48, 2016.

KALICHEVSKY, M. T.; BLANSHARD, J. M. V; TOKARCZUK, P. F. Effect of water content and sugars on the glass transition of casein and sodium caseinate. p. 139-151, 1993.

MAUER L. J.; SMITH D. E.; LABUZA T. P., Effect of water content, temperature and storage on the glass transition, moisture sorption characteristics and stickiness of $\beta$-casein, International Journal of Food Properties, v. 3, p. 233-248, 2000.

MATVEEV Y. I. et al. Glass transition temperature of proteins. Calculation based on the additive contribution method and experimental data, Food Hydrocolloids, v. 1, p. 125-133, 1997.

CHARNOCK, S. C.; McCLEARY, B. V. Assay for determination of free $D$-galactose and /or L-arabinose. Irish Patent $\mathrm{N}^{\circ} \mathrm{S} 84280$, UK Patent $N^{\circ}$. 1828407, German Patent $N^{\circ}$ 1828407, French Patent $N^{\circ} 1828407$ and USA Patent No. US7,785,771/11/722,000, (2006).

MINTEL. Cresce o lançamento de produtos sem lactose no Brasil. Disponível em: $<$ http:// brasil.mintel.com/blog/noticias-mercadoalimentos-bebidas/cresce-lancamento-deprodutos-sem-lactose-no-brasil $>$. Acesso em: 8 mai. 2016.

MORLOCK, G. E.; MORLOCK, L. P.; LEMO, C. Streamlined analysis of lactose-free dairy products. Journal of Chromatography A, v. 1324, p. $215-223,2014$.

PROZYN. Produtos com baixa lactose. Informação técnica. 2015. Disponível em: $<$ http://www.prozyn.com.br>. Acesso em: 15 mai. 2015.

RICHMOND, M. L.; GRAY, J. I.; STINE, C. M. Beta-Galactosidase: Review of Recent Research Related to Technological Application, Nutritional Concerns, and Immobilization. Journal of Dairy Science, v. 64, p. 1759-1771, 1981.

RODRIGUES JUNIOR, P. H. et al. FTRaman and chemometric tools for rapid determination of quality parameters in milk powder: Classification of samples for the presence of lactose and fraud detection by 
addition of maltodextrin. Food Chemistry, v. 196, p. 584-588, 2016.

RONG, Q. et al. Milk consumption and lactose intolerance in adults. Biomedical and Environmental Sciences, v. 24, n. 5, p. $512-517,2011$.

ROOS, Y. H. Melting and glass transitions weight carbohydrates of low molecular. Carbohydrate Research, v. 238, p. 39-48, 1993.

ROOS, Y. H. Importance of glass transition and water activity to spray drying and stability of dairy powders. Lait, v. 82, p. 475-484, 2002.

ROOS, Y. H; KAREL, M. Plasticizing Effect of Water on Thermal Behavior and Crystallization of Amorphous Food Models. Journal of Food Science, v. 56, n. 1, p. 3843, 1991.

SENOUSSI, A.; DUMOULIN, E. D.; BERK, Z. Retention of Diacetyl in Milk during
Spray-Drying and Storage. Journal of Food Science, v. 60, n. 5, p. 894-897, 1995.

SCHUCK, P. Material Didático do Curso: Concentration, Crystallization, Spray Drying e Rehydration. Viçosa, 2016.

SCHUCK, P. et al. Water activity and glass transition in dairy ingredients. Lait, v. 85, p. 295-304, 2005a.

SCHUCK, P. et al. Thermohygrometric sensor: A tool for optimizing the spray drying process. Innovative Food Science and Emerging Technologies, v. 6, n. 1, p. 45-50, 2005b.

SHRESTHA, A. K. et al. Water sorption and glass transition properties of spray dried lactose hydrolysed skim milk powder. LWT - Food Science and Technology, v. 40, n. 9, p. 1593-1600, 2007.

SWALLOW, D. M. Genetics of lactase persistence and lactose intolerance. Annual review of genetics, v. 37, p. 197-219, 2003. 